\title{
Novos padrões de investigação policial no Brasil
}

Arthur Trindade Maranhão Costa

\& Almir de Oliveira Júnior*

Resumo: Neste artigo, descrevemos algumas das principais características dos casos de investigação policial que foram denunciados pelo Ministério Público Estadual. O padrão que emerge dos dados da pesquisa realizada em nove estados brasileiros, a partir de uma amostra dos processos criminais arquivados em 2011, difere das representações tradicionais da investigação baseada na busca de testemunhas e produção de depoimentos e confissões. As prisões em flagrante ocupam lugar de destaque na instrução criminal e tem efeitos significativos nas sentenças. Ao final, sugerimos que este novo padrão de investigação policial pode ser resultado das mudanças de atitudes dos profissionais do Sistema de Justiça Criminal.

Palavras-chave: polícia, investigação criminal, prisão em flagrante, fluxo de justiça, instrução criminal.

\section{Introdução}

A quilo que chamamos de investigação criminal, seus objetivos, métodos e rotinas tem mudado profundamente ao longo da história. Portanto, para entender o que vem a ser investigação criminal, e suas mudanças ao longo do tempo, é necessário compreender o contexto político, social e cultural no qual ela se insere.

Podemos encontrar exemplos de práticas associadas à investigação criminal ao longo da história de várias sociedades. Entretanto, aquilo que chamamos de investigação criminal, ou seja, a aplicação de rotinas e técnicas por parte de um corpo policial, para identificação de suspeitos e produção de provas jurídicas, data do final do século XIX (Morris, 2007). Antes disso, a produção de provas e a identificação de suspeitos era uma questão privada, às vezes empreendida por agentes privados pagos por recompensa.

Foi somente com a criação das polícias modernas que a investigação criminal passou a ser entendida como obrigação do Estado. Embora as polícias tenham inicialmente orientado suas tarefas para a manutenção da ordem e a vigilância das ruas, a função de investigar crimes foi, aos poucos, sendo incorporada às suas atribuições. De forma que, no início do século XX, boa parte das polícias ocidentais já contava
Recebido: 20.01.14

Aprovado: 09.12.14

\author{
* Arthur Trindade \\ Maranhão Costa \\ é professor do \\ Departamento \\ de Sociologia \\ da Universidade \\ de Brasília e \\ pesquisador do \\ CNPq.<arthur@unb. \\ $b r>$. Almir de Oliveira \\ Júnior, doutor em \\ sociologia e política \\ (UFMG), integrante \\ do Instituto de \\ Pesquisa Econômica \\ Aplicada (Ipea). \\ <almir.junior@ipea. \\ gov.br>
}


1. As atividades de inteligência policial não são orientadas necessariamente, para instrução do processo criminal, mas sim para estabelecer se determinadas pessoas ou grupos estão ou não engajados em atividades criminosas e tentar dissuadilas antes que essas ocorram (Maguire, 2000). Também se refere ao tratamento sistemático de informações e produção de conhecimento a partir do estabelecimento de correlações entre fatos delituosos, ou situações de imediata ou potencial influência sobre eles, produzindo parâmetros de padrões e tendências da criminalidade em determinado contexto de alguma localidade ou região, o que pode fornecer subsídios que facilitam os trabalhos de investigação criminal (Ferro, 2006) com grupos ou unidades dedicadas à investigação criminal (Morris, 2007). Desde então, a investigação criminal tornou-se uma das principais funções desempenhadas pelas polícias, que passaram a se incumbir das seguintes tarefas: (a) identificar e interrogar suspeitos, (b) produzir provas jurídicas; e (c) instruir o processo criminal.

Apesar da enorme visibilidade e glamour que a investigação criminal recebe por parte da mídia e da população em geral, a pesquisa empírica sobre o tema ainda é incipiente. As razões para isto decorrem das dificuldades que os pesquisadores têm encontrado para acessar as unidades de investigação. Policiais têm sido relutantes em proporcionar assistência adequada aos pesquisadores em função das preocupações com segurança e sigilo de suas fontes e de seus procedimentos. Além disso, os dados sobre investigação criminal, quando existentes, são precários, pouco confiáveis e raramente são sistematizados, dificultando as pesquisas quantitativas e qualitativas (Innes 2001).

No Brasil, a literatura sobre o tema é escassa. A maior parte trata da "investigação ideal", como sugere Mingardi (2007). Alguns destes trabalhos descrevem - ou sugerem - métodos e procedimentos de investigação (Ribeiro 2006, 2012; Ferro, 2006). Há também trabalhos que discutem a relação entre a investigação criminal e o processo penal (Ferreira \& Ferreira, 2013). Entretanto, ainda são raras as pesquisas sobre a "investigação real", que acontece no cotidiano das polícias (Mingardi, 1992, 2006, 2007; Mingardi \& Figueiredo, 2009). Além dessas poucas pesquisas, recentemente têm surgido trabalhos sobre as atividades de inteligência policial, que, embora não se confundam com a investigação, guardam estreita relação com esta (Brandão \& Cepik, 2013)1.

Apesar do já mencionado glamour que envolve as atividades de investigação criminal, as unidades encarregadas de investigar crimes sempre conviveram com denúncias de arbitrariedades, práticas ilegais e ineficiência. Mais do que casos isolados de desvio de conduta e fiscalização deficiente, tais críticas refletem uma crise de legitimidade de um modelo de investigação criminal construído ao longo do século $X X$, baseado na entrevista de suspeitos e testemunhas para produção de evidências jurídicas que pudessem resultar em denúncias criminais. Este modelo de investigação criminal segue uma lógica inquisitorial, uma vez que a forma de produção de provas confere pouca ou nenhuma possibilidade de contestação e defesa. As práticas de interrogar suspeitos e testemunhas, visando à obtenção de confissões, tem sido o foco principal destas críticas.

A partir dos anos 1970, essas críticas tornaram-se mais árduas em países como os Estados Unidos, o Canadá e a Inglaterra, resultando em profundas alterações nas práticas de investigação criminal. Decisões judiciais ampliaram as restrições ao uso 
de depoimentos e confissões nos processos criminais. Assim, foi necessário um incremento nos investimentos dos órgãos de perícia, num esforço de priorizar as provas técnicas em detrimento das provas testemunhais (Skolnick \& Fyfe, 1993). No que se refere especificamente às polícias, foram criados manuais de investigação, bem como introduzidos novos procedimentos operacionais para otimizar o desempenho dos investigadores (Maguire, 2003).

Neste artigo, descreveremos algumas das principais características dos casos de investigação policial que foram denunciados pelo Ministério Público Estadual no Brasil. O padrão que emerge dos dados apresentados difere das representações tradicionais da investigação baseada na busca de testemunhas e produção de depoimentos e confissões. Como veremos nas seções seguintes, as prisões em flagrante ocupam lugar de destaque na instrução criminal e têm efeitos significativos nas sentenças. Ao final, sugerimos que este novo padrão de investigação policial pode ser resultado das mudanças de atitudes dos profissionais do Sistema de Justiça Criminal.

\section{A pesquisa}

Os dados utilizados neste artigo foram obtidos na pesquisa "Política criminal alternativa à prisão", realizada pelo Instituto de Pesquisa Econômica Aplicada (Ipea) a pedido do Departamento Penitenciário Nacional (Depen). A pesquisa também contou com o apoio do Conselho Nacional de Justiça (CNJ) e teve a participação dos autores em todas as suas etapas².

Os dados foram levantados a partir das informações dos processos transitados em julgado e arquivados (autos findos) de varas criminais localizadas em nove unidades da federação: Distrito Federal, Espírito Santo, Minas Gerais, Pará, Paraná, Pernambuco, Rio Grande do Sul, Rio de Janeiro e São Paulo. O objetivo central era levantar informações relevantes sobre os registros de processamento dos feitos criminais nos autos processuais, os quais reúnem dados relativos às fases policial e judicial, refletindo, em certa medida, todo o ciclo do Sistema de Justiça Criminal. Para construir as amostras de processos sobre as quais seriam coletadas as informações, foram utilizadas as listas de autos findos arquivados no ano de 2011 (ano de referência) em cada uma das Unidades da Federação (UF) que fazem parte do estudo. As listas foram obtidas diretamente junto aos Tribunais de Justiça dos Estados e do Distrito Federal, contando com apoio do $\mathrm{CNJ}^{3}$.

Dadas as populações originais (número total de processos criminais com baixa em 2011), foram calculados os tamanhos das amostras para cada UF. De posse do número de processos que deveria compor as amostras estaduais, realizou-se sorteio aleatório entre os processos constantes das listas fornecidas pelos Tribunais de
2. Também participaram da pesquisa Alexandre dos Santos Cunha, Bernardo Medeiros, Emília Ferreira, Fábio Sá e Silva, Helder Ferreira, Luseni Aquino, Pedro Vicente da Silva Neto, Talita Rampin, Tatiana Daré Araújo, Vitor Silva Alencar, Renato Sérgio de Lima e Rebecca Lemos Igreja, além da equipe para coleta de dados em campo.

3. O CNJ

solicitou ainda o desarquivamento dos autos para que ficassem à disposição dos pesquisadores. Isso só foi possível com a introdução da numeração única dos processos judiciais a partir de 2009. Desde então, todos as ações judiciais (federais ou estaduais) recebem uma numeração fornecida pelo CNJ na qual é possível identificar o tipo de ação (civil ou criminal), a comarca, a vara e o número do processo. 
TABELA 1

COMARCAS E PROCESSOS

PESQUISADOS POR UF

4. A limitação da amostra em função do critério populacional se justifica em virtude de o número e a variedade de processos criminais serem mais expressivos nos municípios maiores, o que facilitou a organização logística da pesquisa.

5. O levantamento das informações foi realizado pela seguinte equipe de campo: Alessandra de Almeida Braga, Amílcar Cardoso Vilaça de Freitas, Andréa Caon Reolão Stobbe, Carolina Cutrupi Ferreira, Dineia Largo Anziliero, Erica Santoro Lins Ferraz, Fabio Henrique Araujo Martins, Klarissa Almeida Silva, Marcelo Ottoni Durante, Tatiana Santos Perrone, Walison Vasconcelos Pascoal, Wilson Santos de Vasconcelos, Yuri Frederico Dutra.
Justiça, considerando-se exclusivamente aqueles baixados em varas criminais e juizados especiais criminais de comarcas com população superior a 100 mil habitantes. No total, foram selecionados 2.344 processos distribuídos conforme a Tabela $1^{4}$.

A coleta de informações foi realizada por equipes distribuídas por estados. Para isso, os(as) pesquisadores(as) se valeram de um espeIho de dados contendo questões sobre: (a) o fato criminoso; (b) o inquérito policial; (c) as características sociodemográficas do(s) investigado(s); (d) os antecedentes criminais dos investigado(s); (e) a instrução do processo; (f) o julgamento; e (g) o cumprimento da pena. Apesar de não ser estatisticamente representativa das 27 unidades da Federação, a amostra é abrangente o suficiente para que possamos descrever o quadro da investigação criminal no Brasil ${ }^{5}$.

\section{O mito da investigação criminal}

A investigação criminal, desde sua criação, tem sido objeto de enorme interesse do público em geral, e permanece cingida de vários mitos. Esse interesse pode ser explicado não apenas pelo glamour da ideia de prender criminosos, mas também pela importância que a investigação assumiu ao dar forma à promessa do Estado moderno de prover segurança para todos os cidadãos (Garland, 1996; 2001).

De fato, a investigação criminal tem desempenhado duas funções críticas relacionadas à promessa estatal de segurança. Em primeiro lugar, ela é a principal "porta de entrada" do Sistema de Justiça Criminal. Embora existam outras situações que prescindam da polícia, a maioria dos processos criminais tem origem no inquérito policial. Ademais, a investigação desempenha papel central na função de dissuadir a prática de crimes; ela certamente é a iniciativa mais visível dos esforços policiais para dar uma resposta convincente à sociedade.

Dada sua dimensão simbólica, a investigação tem sido retratada como a forma mais efetiva de elucidar crimes e punir criminosos. Para isso, criou-se uma imagem estereotipada da atividade de investigação descrita por Mike Maguire (2003) como o 
"mito de Sherlock Holmes". Tal mito envolve uma sequência de ações: (a) alguém relata um crime à polícia, (b) os investigadores examinam a cena do crime e interrogam pessoas e (c) o suspeito é identificado e confrontado com provas irrefutáveis sobre sua culpa, resultando numa confissão e posterior denúncia criminal. Entretanto, as pesquisas mostram que as práticas de investigação constituem um quadro radicalmente diferente.

Nem sempre os crimes são relatados à polícia pelas vítimas. Frequentemente os policiais tomam conhecimentos dos crimes através da mídia e de terceiros. Além disso, em grande parte dos casos, o simples relato de crimes não implica no início de uma investigação criminal. Alguns casos serão arquivados e outros serão processados na forma de estatísticas criminais. Noutras palavras, a investigação criminal é uma atividade altamente seletiva.

No Brasil, apesar de a legislação indicar a necessidade de instauração de inquérito policial sobre todas as notícias-crime, na prática não é bem assim que acontece numa delegacia de polícia (cf. Misse, 2010a). Nem todas as notícias de crime se convertem em boletins de ocorrência; nem todas as ocorrências são transformadas em inquéritos policiais. Fatores ligados à repercussão do crime e ao status social das vítimas contribuem significativamente para a instauração dos inquéritos. Entretanto, de forma geral, a lógica de seleção dos casos refere-se muito mais à necessidade que os delegados e agentes de polícia têm de administrar o volume de trabalho (Costa, 2011).

O exame da cena do crime não é a regra da investigação criminal. São raros os casos de os investigadores se dirigem à cena do crime, entrevistarem pessoas e realizarem diligências para identificar os suspeitos. Frequentemente, os autores são denunciados diretamente pela população. Nesses casos, o trabalho da polícia se limita a preparar um inquérito para instruir o processo criminal. Ou seja, o processo criminal pode ser instruído sem que necessariamente tenha ocorrido previamente uma investigação criminal.

A instauração de um inquérito policial implica a realização de muito trabalho, tanto no que diz respeito à investigação policial, quanto aos procedimentos burocráticos. Uma vez que número de ocorrências numa delegacia de polícia normalmente é muito grande, apenas nos casos de flagrante ou de homicídios dolosos os inquéritos são obrigatoriamente instaurados. Nos demais casos, os policiais priorizam os boletins de ocorrência que já trazem elementos de prova necessários para a conclusão de um inquérito (informações sobre a autoria do crime, com filmagens, depoimentos, testemunhas, registros diversos). Nessas situações, não se realiza de fato uma investigação criminal para identificar suspeitos e produzir evidências, pois 
essas informações já foram fornecidas pela vítima. O trabalho da polícia, nesses casos específicos, é reproduzir essas informações no inquérito que irá instruir o processo criminal.

Portanto, é a necessidade de administrar o trabalho que rege a seleção dos casos a serem investigados. Existindo informações suficientes no boletim de ocorrência, instaura-se o inquérito sem a realização de investigação, caso contrário, arquiva-se a ocorrência. Portanto, a investigação criminal não é uma regra, mas uma exceção.

A polícia não procede de forma neutra na busca da verdade. Tampouco os fatos relatados e as provas coletadas durante a investigação são irrefutáveis. Frequentemente, os suspeitos são identificados (ou eleitos) previamente. Nessas situações, o trabalho da polícia é produzir provas que sustentem aquela incriminação previamente realizada.

A despeito de a legislação e a doutrina jurídica brasileiras enfatizarem que não compete às polícias a tarefa de incriminar suspeitos, na prática sabemos que a investigação criminal parte de uma lógica inversa. As evidências que serviram para instruir o processo, portanto, para incriminar os suspeitos, são produzidas pela polícia depois de sua identificação. Desta forma, como apontam Kant de Lima (1995) e Misse (2010), a investigação criminal exerce papel central na formação da culpa.

\section{Analisando o trabalho da polícia}

Ao verificar o conjunto dos processos examinados nesta pesquisa, constatamos que $57,6 \%$ deles foram instruídos por um inquérito instaurado através da prisão em flagrante dos suspeitos e 33,9\% por inquéritos iniciados por portaria (Tabela 2). Além disso, em outros 147 (6,8\%), os acusados já se encontravam presos por motivos alheios ao processo (Tabela 3). Ou seja, em 64,4\% dos casos válidos para análise, os acusados

TABELA 2

FORMA DE INSTAURAÇÃO DO INQUÉRITO

\begin{tabular}{|c|c|c|c|}
\cline { 2 - 4 } \multicolumn{1}{c|}{} & Frequência & \% Válida & \% Acumulada \\
\hline Flagrante & 1.258 & 57,6 & 57,6 \\
\hline Portaria & 740 & 33,9 & 91,5 \\
\hline Outro & 127 & 5,8 & 97,3 \\
\hline N/I & 58 & 2,7 & 100,0 \\
\hline N/A & 161 & & \\
\hline Total & 2.344 & & \\
\hline
\end{tabular}

TABELA 3

RÉU PRESO POR

\begin{tabular}{|c|c|c|c|}
\hline & \multicolumn{3}{|c|}{ MOTIVOS ALHEIOS AO CASO } \\
\hline & Frequência & \% Válida & \% Acumulada \\
\hline Não & 2.011 & 93,2 & 93,2 \\
\hline Sim & 147 & 6,8 & 100,0 \\
\hline N/A & 186 & & \\
\hline Total & 2.344 & & \\
\hline
\end{tabular}


já se encontravam presos no momento da instauração dos inquéritos policiais.

Também é interessante notar que em $89,0 \%$ dos processos analisados, apenas uma pessoa foi indiciada pelo crime (Tabela 4). O percentual inclui os casos de tráfico de drogas e crime organizado, cujo trabalho da polícia supostamente deveria indi-

TABELA 4

NÚMERO DE INDICIADOS

\begin{tabular}{|c|c|c|c|}
\hline & Frequência & \% Válida & $\%$ Acumulada \\
\hline 1 & 2.086 & 89,0 & 89,0 \\
\hline 2 & 51 & 2,2 & 91,2 \\
\hline 3 & 15 & 0,6 & 91,8 \\
\hline 4 & 6 & 0,3 & 92,1 \\
\hline$>4$ & 186 & 7,9 & 100,0 \\
\hline Total & 2.344 & 100,0 & \\
\hline
\end{tabular}

car a ação criminosa de duas ou mais pessoas.

Ao considerar ainda o trabalho da polícia, podemos verificar que, em $86,06 \%$ dos processos selecionados, não houve dificuldade em localizar autores, vítimas ou testemunhas (Tabela 5). Dentre os poucos casos que os processos indicam problemas com a localização de pessoas (13,94\%), a maior dificuldade registrada foi quanto à localização do autor $(88,49 \%)$, seguida à de testemunhas (11,51\%). Em nenhum dos processos selecionados houve dificuldade para localizar a(s) vítima(s) (Tabela 6).

Essas estatísticas, contudo, precisam ser interpretadas com cuidado. A pesquisa não analisou todos os crimes registrados pela polícia civil, apenas aqueles que foram denunciados pelo Ministério Público (MP). Assim, podemos dizer que os inquéritos que resultaram em denúncia criminal foram aqueles em que os policiais tiveram menos dificuldade em localizar as pessoas.
TABELA 5

HOUVE DIFICULDADE EM LOCALIZAR

PESSOAS NA FASE POLICIAL?

\begin{tabular}{|c|c|c|c|}
\cline { 2 - 4 } \multicolumn{1}{c|}{} & Frequência & $\%$ Válida & $\%$ Acumulada \\
\hline Não & 1.877 & 86,1 & 86,1 \\
\hline Sim & 304 & 13,9 & 100,0 \\
\hline N/A & 163 & & \\
\hline Total & 2.344 & & \\
\hline
\end{tabular}

TABELA 6

HOUVE DIFICULDADE DE

LOCALIZAR AUTOR, VÍTIMA OU TESTEMUNHA?

\begin{tabular}{|c|r|r|r|}
\cline { 2 - 4 } \multicolumn{1}{c|}{} & Frequência & $\%$ Válida & \% Acumulada \\
\hline Autor & 269 & 88,5 & 88,5 \\
\hline Testemunha & 35 & 11,5 & 100,0 \\
\hline Vítima & 0 & 0,0 & 100,0 \\
\hline N/A & 2.040 & & \\
\hline Total & 2.344 & & \\
\hline Fonte: Diest/lpea. & & & \\
\hline
\end{tabular}

TABELA 7

NÚMERO DE VEZES QUE O INQUÉRITO POLICIAL RETORNOU

\begin{tabular}{|c|r|r|r|}
\cline { 2 - 4 } \multicolumn{1}{l|}{} & Frequência & \% Válida & \% Acumulada \\
\hline 0 & 1.610 & 74,5 & 74,5 \\
\hline 1 & 281 & 13,0 & 87,6 \\
\hline 2 & 105 & 4,9 & 92,4 \\
\hline 3 & 49 & 2,3 & 94,7 \\
\hline 4 & 32 & 1,5 & 96,2 \\
\hline 5 & 20 & 0,9 & 97,2 \\
\hline$>5$ & 62 & 2,8 & 99,9 \\
\hline N/I & 1 & 0,1 & 100,0 \\
\hline N/A & 184 & 100,0 & \\
\hline Total & 2.344 & & \\
\hline
\end{tabular}


Outro aspecto importante que deve ser destacado refere-se ao reduzido número de inquéritos que foram devolvidos pelo MP para mais diligências. Em 74,5\% dos processos analisados, o MP aceitou o relatório final elaborado pelo delegado (Tabela 7). Em 87,6\% das ocorrências, o inquérito foi devolvido à polícia no máximo duas vezes. Portanto, podemos dizer que os inquéritos que mais frequentemente dão origem a processos criminais são aqueles que não necessitam de novas investigações. Talvez isso aconteça devido ao elevado número de prisões em flagrante.

\section{A organização da investigação criminal}

Podemos identificar pelo menos duas estruturas organizacionais para investigar crimes. Existem, inicialmente, as unidades generalistas de investigação, encarregadas de elucidar vários tipos de crimes. Essas unidades empregam, em regra, um pequeno número de investigadores e têm sua jurisdição delimitada territorialmente.

O trabalho dessas unidades é voltado para responder às ocorrências que são relatadas pela população. É, portanto, um trabalho eminentemente reativo. A rotina das unidades generalistas consiste na recepção do diário de ocorrências criminais e na seleção de casos a serem investigados por pequenas equipes de policiais. Não há divisão clara de trabalho entre os investigadores, que são responsáveis pela execução de todas as tarefas afetas à investigação, tais como interrogar suspeitos, entrevistar pessoas, examinar a cena do crime, produzir relatórios, solicitar exames periciais e encaminhar requerimentos. Os policiais que trabalham nessas unidades não seguem necessariamente uma ordem de casos a serem investigados. Frequentemente, os investigadores desenvolvem atividades relacionadas a vários casos simultaneamente, o que certamente compromete o resultado das diligências (Maguire, 1994; Innes, 2007).

Talvez seja por isso que boa parte do trabalho dessas unidades esteja voltada para a busca dos suspeitos já conhecidos dos policiais. Trata-se de uma forma de "policiamento por suspeição" (Misse, 2010a). Assim, as atividades de investigação concentram-se na coleta e sistematização de informações sobre as pessoas com registros criminais, na expectativa de estabelecimento de uma relação entre as atividades dessas pessoas com as ocorrências criminais em análise.

Já as unidades especializadas de investigação concentram-se na elucidação de crimes específicos. O principal argumento para criação dessas unidades é que certos tipos de crimes seguem lógicas próprias e requerem, portanto, rotinas e procedimentos específicos. Em alguns casos, como nos crimes ambientais e tributários, não é frequente o recebimento de denúncias da população. Nessas ocorrências, é necessária uma postura proativa da polícia. Já nos casos dos crimes de roubo de veí- 
culos e fraudes, a polícia age de forma reativa. Em ambas as situações, as atividades de investigação envolvem grandes esforços na produção de inteligência, ou seja, de informações que não são necessariamente voltadas para o esclarecimento de ocorrências ou para a instrução do processo criminal (Maguire, 2000).

As atividades de investigação das unidades especializadas concentram-se na busca de informações sobre as rotinas, os contatos e os negócios dos grupos suspeitos de atividades criminosas. Esse tipo de tarefa impõe aos policiais a necessidade de contatos próximos com pessoas ou grupos criminosos. Sem um sistema de controle e fiscalização adequado, tais tarefas acabam possibilitando a ocorrência de casos de corrupção.

Esta pesquisa mostra que, de forma geral, os inquéritos foram instaurados e concluídos por delegacias generalistas $(77,4 \%)$ e não por delegacias especializadas $(22,6 \%)$, conforme mostra a Tabela 8. Ou seja, foram realizados no âmbito de delegacias cuja competência abrange um número muito grande de responsabilidades, onde são geralmente escassos os efetivos e os meios disponíveis

TABELA 8

INQUÉRITO POLICIAL CONCLUÍDO POR DELEGACIA ESPECIALIZADA?

\begin{tabular}{|l|c|c|c|}
\cline { 2 - 4 } \multicolumn{1}{c|}{} & Frequência & $\%$ Válida & \% Acumulada \\
\hline Não & 1.687 & 77,4 & 77,4 \\
\hline Sim & 494 & 22,6 & 100,0 \\
\hline N/A & 163 & & \\
\hline Total & 2.344 & & \\
\hline
\end{tabular}
para a realização de investigações criminais.

Em resumo: a maior parte dos processos analisados foi instruída por inquéritos polícias instaurados a partir de prisões em flagrante (57,6\%). Esses inquéritos, em sua grande maioria, indiciaram apenas uma pessoa (89\%) que a polícia não teve dificuldade em localizar. Além disso, os inquéritos que serviram para instruir os processos criminais foram aqueles concluídos por delegacias não especializadas $(77,4 \%)$ e que a polícia não realizou diligências complementares (74,5\%).

\section{O perfil dos autores}

Com relação ao sexo dos autores, as informações contidas nos processos mostram que $87,6 \%$ dos acusados eram do sexo masculino e 9,4\% feminino (Tabela 9). Já as informações existentes nos processos analisados não são muito precisas em relação à raça/cor dos acusados, uma vez que não foi possível determinar

TABELA 9

PERFIL DOS AUTORES, POR SEXO

\begin{tabular}{|c|c|r|c|}
\cline { 2 - 4 } \multicolumn{1}{c|}{} & Frequência & \multicolumn{1}{c|}{$\%$} & \% Acumulada \\
\hline Masculino & 2.736 & 87,6 & 87,6 \\
\hline Feminino & 294 & 9,4 & 97,0 \\
\hline $\mathrm{N} / \mathrm{I}$ & 93 & 3,0 & 100,0 \\
\hline Total & 3.123 & 100,0 & \\
\hline Fonte: Diest/lpea. & & & \\
\hline
\end{tabular}

a raça/cor dos autores em $30,9 \%$ dos processos. Nos processos que apresentavam 
TABELA 10

PERFIL DOS AUTORES, POR RAÇA/COR

\begin{tabular}{|c|r|r|c|}
\cline { 2 - 4 } \multicolumn{1}{c|}{} & Frequência & \multicolumn{1}{c|}{$\%$} & $\%$ Acumulada \\
\hline Parda & 938 & 30,0 & 30,0 \\
\hline Branca & 904 & 28,9 & 58,9 \\
\hline Negra & 305 & 9,8 & 68,7 \\
\hline Amarela & 7 & 0,2 & 68,9 \\
\hline Indígena & 3 & 0,1 & 69,0 \\
\hline N/I & 966 & 30,9 & 100,0 \\
\hline Total & 3.123 & 100,0 & \\
\hline Fonte: Diest/lpea. & &
\end{tabular}

TABELA 11

PERFIL DOS AUTORES, POR ESTADO CIVIL

\begin{tabular}{|c|r|r|c|}
\cline { 2 - 4 } \multicolumn{1}{c|}{} & Frequência & \multicolumn{1}{c|}{$\%$} & $\%$ Acumulado \\
\hline Solteiro(a) & 1.913 & 61,3 & 61,3 \\
\hline Casado(a) & 448 & 14,3 & 75,6 \\
\hline União Estável & 362 & 11,6 & 87,2 \\
\hline Separado(a) & 98 & 3,1 & 90,3 \\
\hline Viúvo(a) & 20 & 0,6 & 90,9 \\
\hline N/I & 282 & 9,1 & 100,0 \\
\hline Total & 3.123 & 100,0 & \\
\hline Fonte: Diest/Ipea. & & & \\
\hline
\end{tabular}

informações acerca da raça/cor, pode-se observar que 30,0\% dos acusados eram pardos, 28,9\% brancos e 9,8\% negros (Tabela 10).

Se, por um lado, os processos não têm informações precisas sobre a raça/cor dos autores, por outro, as informações sobre seu estado civil estão bem registradas. A Tabela 11 mostra que a maior parte dos autores era de solteiros (61,3\%). Poucos autores eram casados ou tinham algum tipo de união estável (25,9\%).

No que diz respeito à escolaridade, as informações dos processos analisados também não são precisas. Em 30,1\% dos processos, não foi possível verificar o nível de escolaridade dos autores. Naqueles processos que esta informação estava disponível, verificamos que $52,5 \%$ dos acusados possuíam, no máximo, o ensino fundamental completo. Sendo que em $29,9 \%$ dos casos, os autores possuíam ensino fundamental incompleto, conforme mostra a Tabela 12.

TABELA 12

PERFIL DOS AUTORES, POR GRAU DE INSTRUÇÃO

\begin{tabular}{|c|r|r|r|}
\hline Escolaridade & Frequência & \multicolumn{1}{|c|}{$\%$} & \% Acumulado \\
\hline Analfabeto & 65 & 2,1 & 2,1 \\
\hline Sabe ler e escrever & 212 & 6,8 & 8,9 \\
\hline Ensino fundamental incompleto & 934 & 29,9 & 38,8 \\
\hline Ensino fundamental completo & 427 & 13,7 & 52,5 \\
\hline Ensino médio incompleto & $1 \mathrm{~N} / \mathrm{I}$ & 6,4 & 58,8 \\
\hline Ensino médio completo & 243 & 7,8 & 66,6 \\
\hline Ensino superior Incompleto & 37 & 1,2 & 67,8 \\
\hline Ensino superior completo ou pós-graduação & 50 & 1,6 & 69,4 \\
\hline N/I & 956 & 30,6 & 100,0 \\
\hline Total & 3.123 & 100,0 & \\
\hline
\end{tabular}

Fonte: Diest/Ipea. 
Com relação aos antecedentes criminais, notamos um grande número de autores com algum tipo de passagem pelo Sistema de Justiça Criminal. Verificamos que $33,7 \%$ dos autores já haviam sido presos antes do fato,
TABELA 13

PASSAgem PELO Sistema de Justiça CRIMINAL

\begin{tabular}{|c|c|r|r|r|r|r|}
\cline { 2 - 8 } \multicolumn{1}{c|}{} & \multicolumn{2}{|c|}{ Já foi preso? } & \multicolumn{2}{c|}{ Já foi processado? } & \multicolumn{2}{c|}{ Já foi condenado? } \\
\cline { 2 - 8 } & Frequência & \multicolumn{1}{|c|}{$\%$} & Frequência & \multicolumn{1}{c|}{$\%$} & Frequência & $\%$ \\
\hline Não & 1.232 & 39,4 & 1.178 & 37,7 & 1.647 & 52,7 \\
\hline Sim & 1054 & 33,7 & 1.181 & 37,8 & 648 & 20,7 \\
\hline N/A & 684 & 21,9 & 692 & 22,2 & 693 & 22,2 \\
\hline N/I & 153 & 4,9 & 72 & 2,3 & 135 & 4,3 \\
\hline Total & 3.123 & 100,0 & 3.123 & 100,0 & 3.123 & 100,0 \\
\hline
\end{tabular}

Fonte: Diest/Ipea.

TABELA 14

JÁ RECEBEU ALGUM BENEFÍCIO ANTES DO FATO?

\begin{tabular}{|c|c|r|c|}
\cline { 2 - 4 } \multicolumn{1}{c|}{} & Frequência & \multicolumn{1}{c|}{$\%$} & $\%$ Acumulado \\
\hline Não & 1.161 & 37,2 & 37,2 \\
\hline Sim & 1962 & 62,8 & 100,0 \\
\hline Total & 3.123 & 100,0 & \\
\hline
\end{tabular}

$37,8 \%$ já haviam sido processados e $20,7 \%$ já haviam sido condenados (Tabela 13). Ou seja, chama a atenção o fato de que a maioria dos acusados já tinha passado pelo Sistema de Justiça Criminal e 62,8\% dos autores já havia recebido algum tipo de benefício penal, conforme mostra a Tabela 14.

Portanto, nos casos analisados na pesquisa, a maioria dos autores era do sexo masculino $(87,6 \%)$, solteiros $(61,3 \%)$, que cursaram, no máximo, o ensino fundamental $52,5 \%)$. Muitos deles já tiveram algum tipo de passagem pelo Sistema de Justiça Criminal (prisão, denúncia ou condenação) e a maioria já havia recebido algum tipo de benefício penal (62,8\%).

\section{O Ministério Público e a denúncia criminal}

Como sabemos, a promotoria é a "titular da ação penal", portanto, tem autonomia para julgar se os fatos relatados no inquérito policial devem ou não ser denunciados. Isto implica dizer que promotor e delegado podem divergir sobre os aspectos jurídicos dos casos apresentados. O mesmo acontece com o juiz criminal, que pode divergir sobre a interpretação do delegado e do promotor e decidir não aceitar a denúncia. De acordo com a pesquisa, o(a) juiz(a) aceitou a denúncia em $79,8 \%$ dos processos. Noutros

TABELA 15 HOUVE RECEBIMENTO 9,2\% dos casos, o(a) juiz(a) não aceitou a denúncia apresentada pelo MP (Tabela 15).

É importante notar que 43,2\% dos processos analisados corriam com o réu preso no momento da denúncia. Ou seja, em 54,1\% dos 1.870 processos com denúncias aceitas, 0
DA DENÚNCIA PELO JUIZ?

\begin{tabular}{|c|c|r|c|}
\cline { 2 - 4 } \multicolumn{1}{c|}{} & Frequência & \multicolumn{1}{c|}{$\%$} & \% Acumulada \\
\hline Não & 217 & 9,2 & 9,2 \\
\hline Sim & 1.870 & 79,8 & 89,0 \\
\hline N/A & 257 & 11,0 & 100,0 \\
\hline Total & 2.344 & 100,0 & \\
\hline
\end{tabular}


TABELA 16

O PROCESSO CORRE CONTRA

O RÉU PRESO NO MOMENTO?

\begin{tabular}{|c|r|r|r|}
\cline { 2 - 4 } \multicolumn{1}{c|}{} & Frequência & \multicolumn{1}{c|}{$\%$} & $\%$ Acumulada \\
\hline Não & 842 & 35,9 & 35,9 \\
\hline Sim & 1.012 & 43,2 & 79,1 \\
\hline N/A & 470 & 20,1 & 99,1 \\
\hline N/I & 20 & 0,9 & 100,0 \\
\hline Total & 2.344 & 100,0 & \\
\hline Fonte: Diest/Ipea.
\end{tabular}

TABELA 17

O PROCESSO CORRE CONTRA RÉU PRESO, POR TIPO DE INSTAURAÇÃO DE INQUÉRITO POLICIAL

\begin{tabular}{|c|c|c|c|c|c|c|}
\cline { 2 - 7 } \multicolumn{1}{c|}{} & \multicolumn{2}{c|}{ Réu em liberdade } & \multicolumn{2}{c|}{ Réu preso } & \multicolumn{2}{c|}{ Total } \\
\cline { 2 - 7 } & Frequência & \multicolumn{1}{c|}{$\%$} & Frequência & \multicolumn{1}{c|}{$\%$} & Frequência & $\%$ \\
\hline Flagrante & 318 & 39,1 & 874 & 86,9 & 1.192 & 65,5 \\
\hline Portaria & 431 & 52,9 & 124 & 12,3 & 555 & 30,5 \\
\hline Outro & 65 & 8,0 & 8 & 0,8 & 73 & 4,0 \\
\hline Total & 814 & 100,0 & 1.006 & 100,0 & 1.820 & 100,0 \\
\hline Fonte: Diest/Ipea. & & & & & & \\
\hline
\end{tabular}
$(54,1 \%)$, sendo que a grande maioria dessas prisões ocorreu na fase policial $(86,9 \%)$. Ademais, na maior parte dos casos de prisão em flagrante $(73,3 \%)$, os acusados são mantidos presos ao longo do processo.

\section{As sentenças}

Quanto às sentenças, verificamos que $46,8 \%$ dos réus denunciados foram conde-

TABELA 18

TIPO DE SENTENÇA

\begin{tabular}{|c|r|r|r|}
\cline { 2 - 4 } \multicolumn{1}{c|}{} & Frequência & $\%$ & $\%$ Acumulada \\
\hline Condenação a pena privativa de liberdade & 1.106 & 46,8 & 46,8 \\
\hline Absolvição & 467 & 19,7 & 66,5 \\
\hline Condenação a pena alternativa & 288 & 12,2 & 78,7 \\
\hline Medida alternativa & 143 & 6,0 & 84,8 \\
\hline Medida de segurança & 5 & 0,2 & 85,0 \\
\hline Arquivamento & 163 & 6,9 & 91,9 \\
\hline Desistência da vítima & 6 & 0,3 & 92,1 \\
\hline Prescrição & 187 & 7,9 & 100,0 \\
\hline Total & 2.365 & 100,0 & \\
\hline
\end{tabular}

Assim, podemos dizer que a prisão provisória é a regra e não a exceção no Sistema de Justiça Brasileiro. Mais da metade dos processos com denúncia aceita concerne presos provisórios réu já estava preso (Tabela 16). Verificamos processos que correram com o réu preso. Ou seja, são raros os casos em que houve prisão na fase judicial. Por outro lado, também verificamos que $73,3 \%$ dos presos em flagrante a prisão provisória mantida na fase policial (Tabela 17). Também são poucos os casos de relaxamento da prisão provisória. 
TABELA 19

TIPO DE SENTENÇA E PRISÃO PROVISÓRIA

\begin{tabular}{|c|r|r|r|r|}
\cline { 2 - 5 } \multicolumn{1}{c|}{} & \multicolumn{4}{c|}{ Prisão provisória } \\
\cline { 2 - 5 } \multicolumn{1}{c|}{} & \multicolumn{2}{|c|}{ Não } & \multicolumn{2}{c|}{ Sim } \\
\hline Tipo de sentença & Frequência & \multicolumn{1}{c|}{$\%$} & Frequência & \multicolumn{1}{c|}{$\%$} \\
\hline Condenação a pena privativa de liberdade & 254 & 25,2 & 852 & 62,8 \\
\hline Absolvição & 232 & 23,0 & 235 & 17,3 \\
\hline Condenação a pena alternativa & 160 & 15,9 & 128 & 9,4 \\
\hline Medida alternativa & 102 & 10,1 & 41 & 3,0 \\
\hline Medida de segurança & 2 & 0,2 & 3 & 0,2 \\
\hline Arquivamento & 114 & 11,3 & 49 & 3,6 \\
\hline Prescrição & 138 & 13,7 & 49 & 3,6 \\
\hline Desistência da vítima & 6 & 0,6 & 0 & 0,0 \\
\hline Total & 1.008 & 100,0 & 1.357 & 100,0 \\
\hline Fonte: Diest/Ipea. & & & & \\
\hline
\end{tabular}

0,2\% cumpriram medidas de segurança. Ou seja, $85 \%$ dos réus receberam algum tipo de sentença definitiva. Outros $15 \%$ dos réus não tiveram sentença de mérito, receberam apenas sentenças terminativas (arquivamento, desistência e prescrição).

Podemos observar que $62,8 \%$ dos réus que cumpriam prisão provisória foram condenados a penas privativas de liberdade e 17,3\% foram absolvidos (Tabela 19). Poucos presos provisórios foram condenados a penas alternativas $(9,4 \%)$ ou tiveram que cumprir medidas alternativas (3,0\%). Ou seja, a grande maioria foi sentenciada a pena de prisão. Apenas $7,2 \%$ dos réus não tiveram algum tipo de sentença de mérito. Eles tiveram os processos arquivados por prescrição ou outro motivo.

Já os réus que responderam os processos em liberdade tiveram uma maior distribuição dos tipos de sentença: 25,2\% foram condenados à prisão, 23\% foram absolvidos e $26,0 \%$ foram condenados a penas ou medidas alternativas. Também é importante notar que $25,6 \%$ desses réus tiveram seus processos arquivados ou prescritos.

Constata-se, portanto, que a pena privativa de liberdade é a sentença mais frequente $(46,8 \%$ ). Além disso, verificamos que $92,8 \%$ dos réus que cumpriram prisão provisória receberam uma sentença definitiva, ao passo que entre os réus que responderam o processo em liberdade, apenas $74,4 \%$ chegaram a uma sentença definitiva. Dentre o total de processos que tinham sido arquivados, 72,5\% correram com o réu em liberdade. Ao que parece, a manutenção da prisão provisória na fase judicial tem forte influência na produção da sentença judicial. 


\section{Os tempos do processo criminal}

Quanto à duração dos trabalhos policiais, verificamos que o tempo médio entre a instauração do inquérito policial e a denúncia do MP é de 135 dias (4,5 meses). Nos casos de flagrante, no entanto, o MP apresentou sua denúncia 26 dias após a instauração

TABELA 20

TEMPO ENTRE A INSTAURAÇÃO DO

INQUÉRITO POLICIAL E A SENTENÇA

(EM DIAS)

\begin{tabular}{|c|c|}
\cline { 2 - 2 } \multicolumn{1}{c|}{} & Tempo \\
\hline Flagrante & 26,3 \\
\hline Portaria & 310,3 \\
\hline Total & 135,1 \\
\hline Fonte: Diest/Ipea.
\end{tabular}

TABELA 21

TEMPO ENTRE

DENÚNCIA E SENTENÇA

(EM MESES)

\begin{tabular}{|c|c|}
\cline { 2 - 2 } \multicolumn{1}{c|}{} & Tempo \\
\hline Réu preso & 16,7 \\
\hline Réu solto & 40,6 \\
\hline Média geral & 22,0 \\
\hline
\end{tabular}

do inquérito policial. Já nos casos de portaria, esse tempo foi de 310 dias (Tabela 20). Ou seja, os réus ficam bastante tempo presos sem uma denúncia formal contra eles.

O tempo médio entre o oferecimento da denúncia pelo MP e a emissão de uma sentença de extinção do processo é de 22 meses, quase dois anos (Tabela 21). Como a legislação prioriza a tramitação dos processos que correm com réu preso, o tempo médio dos processos com réu preso é substantivamente menor do que nos processos com réu em liberdade: 16,7 meses para os primeiros e 40,6 meses para os últimos.

TABELA 22

TEMPO ENTRE INSTAURAÇÃO DO INQUÉRITO POLICIAL E A SENTENÇA

(EM MESES)

\begin{tabular}{|c|c|}
\cline { 2 - 2 } \multicolumn{1}{c|}{} & Tempo \\
\hline Flagrante & 21,4 \\
\hline Portaria & 56,0 \\
\hline Total & 33,5 \\
\hline
\end{tabular}

O tempo médio entre a instauração do inquérito e a sentença de extinção do processo é de 33,5 meses (Tabela 22). Nos casos de inquéritos instaurados através de portaria, o tempo médio foi de 56 meses. Já nos casos de flagrantes, com réu preso por prisão provisória, o tempo médio entre a instauração do inquérito policial e a sentença é de 21,4 meses. Portanto, o tempo médio da prisão provisória é de quase dois anos. 


\section{Conclusão}

Podemos dizer que no Brasil são raros os processos criminais que resultaram de trabalhos de investigação criminal. Na maior parte dos casos denunciados, não houve efetivamente trabalho de investigação criminal, pois os acusados foram presos em flagrante $(53,7 \%)$ ou já estavam presos por outros crimes (6,3\%). Exatamente por isso, não houve dificuldade em encontrar as pessoas denunciadas pelo MP $(80,1 \%)$. Grande parte desses inquéritos foi concluída por delegacias não especializadas (72\%).

A maioria dos inquéritos que resultou em denúncias foi aceita de imediato pelo MP, sendo que em $89 \%$ deles havia apenas uma pessoa indiciada. Os réus, em regra, tinham algum tipo de passagem pela polícia, sendo que 62,8\% já haviam recebido algum benefício penal.

Esse padrão de atuação da polícia teve efeitos significativos sobre a tramitação dos processos criminais, pois foram raros os casos de relaxamento das prisões provisórias. A maior parte das pessoas presas em flagrante teve sua prisão provisória mantida durante o processo (73,3\%), cujo tempo médio para os casos de réus presos foi de 21,4 meses. Também verificamos que a manutenção da prisão provisória na fase judicial teve forte influência na produção da sentença judicial, pois apenas 17,3\% dos réus presos foram absolvidos ao final do processo.

O quadro da investigação criminal que realizamos não parece mais se encaixar no padrão descrito por juristas, pesquisadores e jornalistas. De forma geral, a investigação policial no Brasil tem sido representada pela ênfase na tomada de depoimentos e na busca de confissões (Kant de Lima, 1995; Misse, 2010).

De fato, ao longo do século XX, a investigação criminal baseou-se fundamentalmente na entrevista de suspeitos e testemunhas para produção de evidências jurídicas que pudessem resultar em denúncias criminais. Entretanto, esse modelo de investigação passou a ser fortemente criticado nas últimas décadas. As denúncias frequentes de ilegalidades e brutalidade nas práticas de investigação e a pouca eficiência na condenação de suspeitos acabaram por gerar uma crise de legitimidade da investigação criminal (Maguire, 2003).

Em alguns países (notadamente nos Estados Unidos, Canadá e Inglaterra) essas críticas tornaram-se mais fortes a partir dos anos 1970, resultando numa maior restrição ao uso de depoimentos e confissões nos processos criminais. Assim, passou-se a investir grandes recursos nos órgãos de perícia, num esforço de priorizar as provas técnicas, em detrimento das provas testemunhais. No que se refere especificamen- 
te às polícias, foram criados manuais de investigação, bem como introduziram-se novos procedimentos operacionais para a otimização do desempenho dos investigadores. Alguns países criaram sistemas de indicadores da investigação criminal a partir da sistematização dos dados dos diversos órgãos que compõem o Sistema de Justiça Criminal.

No Brasil, também verificamos, a partir da década de 1990, um novo padrão na investigação criminal. Mas, contrariando as expectativas, a investigação criminal não se tornou mais técnica, baseada em provas periciais e procedimentos operacionais: a prisão em flagrante passou a desempenhar papel central na instrução criminal, substituindo a antiga ênfase na busca de testemunhas, produção de depoimentos e confissões.

Os motivos para esta mudança de padrão ainda precisam ser explicados. Mas, certamente, passam pela resistência das polícias civis em abandonar seu padrão cartorial de atuação, com pouca ênfase nas atividades de investigação e inteligência. Contribui para isso a supervalorização dos saberes jurídicos em detrimento dos saberes policiais que se observa nessas polícias (Misse, 2010a).

Além das resistências dos policiais, notamos também uma mudança de postura dos profissionais do Sistema de Justiça Criminal com relação à investigação criminal. Juízes e promotores têm sido cada vez mais relutantes em aceitar e denunciar casos cuja instrução criminal baseou-se exclusivamente na tomada de depoimentos (Costa, 2010). Essa mudança de postura, de certa forma, afetou as atividades de investigação.

Abstract: In this article, we describe some key features of the cases of police investigation that were denounced by the Public Prosecutor in Brazil. The pattern that emerges from a survey conducted in nine states, with a sample of criminal cases filed in 2011, differs from traditional representations of criminal investigation based on the search of witnesses, statements and confessions. The arrests take prominent place in the criminal investigation and has significant effects in the sentences. Finally, we suggest that this new pattern of police investigation may be the result of changes in the attitudes of Criminal Justice System professionals.

Keywords: police, criminal investigation, arrest, case flow of criminal justice, criminal procedure.

\section{Referências}

BRANDAO, P.; CEPIK, M. (Orgs.). Inteligência de segurança pública: teoria e prática no controle da criminalidade. Niterói: Impetus, 2013.

COSTA, A. T. M. É possível uma política criminal? A discricionariedade no Sistema de Justiça Criminal do DF. Sociedade e Estado, v. 26, p. 97-114, 2011. 
- A discricionariedade do Sistema de Justiça Criminal: uma análise do inquérito policial no Distrito Federa". In: Misse, Michel (Org.). O inquérito policial no Brasil. Rio de Janeiro: Booklink, 2010.

FERREIRA, N. J. C.; FERREIRA, L. H. C. A prova na esfera criminal. In: FERREIRA, N. J. C.; FERREIRA, L. H. C. Investigação criminal: um estudo metodológico. 2. ed. São Paulo: Sicurezza, 2013.

FERRO, A. L. Inteligência de segurança pública e análise criminal. Revista Brasileira de Inteligência, v. 2, n. 2, p. 77-92, 2006.

GARLAND, D. The culture of control. Oxford: Oxford University Press, 2001.

- The limits of sovereign State: strategies of crime control in contemporary society. British Journal of Criminology, v. 36, n. 4, p.445-471, 1996.

INNES, M. Investigation order and major crimes inquire. In: NEWBURN, Tim (Ed.). Handbook of policing. Cullompton: Willan Publishing, 2003.

- Investigating Murder: Detective Work and the Police Response to Criminal Homicide. New York: Oxford University Press, 2003a.

- The process structures of police homicide investigations. British Journal of Sociology, v. 58, p. 669-688, 2002.

- Organizational communication and the symbolic construction of police murder investigation. British Journal of Sociology, v. 42, p. 67-87, 2001.

KANT DE LIMA, R. A polícia da cidade do Rio de Janeiro: seus dilemas e paradoxos. Rio de Janeiro: Forense, 1995.

MAGUIRE, M. Criminal investigation and crime control". In: Newburn, Tim (Ed.). Handbook of Policing. Cullompton: Willan Publishing, 2003.

- Policing by risk and targets: some dimensions and implications of intelligence-led crime control. Policing and Society, v. 9, p. 315-336, 2000.

- Assessing investigative performance: the clear up rate and beyond. Focus, v. 1, n. 4, p. 1-22, 1994.

MINGARDI, G. O trabalho da inteligência no controle do crime organizado. Estudos Avançados, v. 21, p. 51-69, 2007.

Inteligência policial e crime organizado. In: LIMA, Renato Sérgio de; PAULA, Liana de (Orgs.). Segurança pública e violência, p. 41-51. São Paulo: Contexto, 2006.

. Tiras, gansos e trutas. São Paulo: Scritta, 1992. 
MINGARDI, G.; FIGUEIREDO, I. S. A investigação de homicídios: construção de um modelo. "Coleção Segurança com Cidadania", v. 3, p. 173-204, 2009.

MISSE, M. Crime, sujeito e sujeição criminal. Aspectos de uma contribuição analítica sobre a categoria bandido. Lua Nova, v. 79, p. 15-38, 2010.

—. O inquérito policial: uma pesquisa empírica. Rio de Janeiro: Boolink, 2010a.

MORRIS. B. History of criminal investigation. In: NEWBURN, Tim (Ed.). Handbook of Policing. Cullompton: Willan Publishing, 2007.

RIBEIRO, L. J. Não há corpo, mas foi crime. Brasília: Fábrica dos Livros Editora, 2012.

_. Investigação criminal - homicídios. Brasília: Fábrica dos Livros Editora, 2006.

SKOLNICK, J.; FYFE, J. Above the law: police and excessive use of force. New York: The Free Press, 1993. 